\title{
High-Performance nMOSFETs Using a Novel Strained Si/SiGe CMOS Architecture
}

\author{
Sarah H. Olsen, Anthony G. O’Neill, Luke S. Driscoll, Kelvin S. K. Kwa, Sanatan Chattopadhyay, Andrew M. Waite, \\ Yue T. Tang, Alan G. R. Evans, David J. Norris, Anthony G. Cullis, Douglas J. Paul, Member, IEEE, and \\ David J. Robbins
}

\begin{abstract}
Performance enhancements of up to $170 \%$ in drain current, maximum transconductance, and field-effect mobility are presented for nMOSFETs fabricated with strained-Si channels compared with identically processed bulk Si MOSFETs. A novel layer structure comprising $\mathrm{Si}_{/} \mathrm{Si}_{0.7} \mathbf{G e}_{0.3}$ on an $\mathrm{Si}_{0.85} \mathbf{G e}_{0.15}$ virtual substrate (VS) offers improved performance advantages and a strain-compensated structure. A high thermal budget process produces devices having excellent on/off-state drain-current characteristics, transconductance, and subthreshold characteristics. The virtual substrate does not require chemical-mechanical polishing and the same performance enhancement is achieved with and without a titanium salicide process.
\end{abstract}

Index Terms-CMOS, drain-current enhancement, nMOSFETs, self-heating, SiGe, strained silicon, thermal budget, transconductance enhancement, virtual substrate.

\section{INTRODUCTION}

$\mathbf{T}$ HE LAST few years have seen the $\mathrm{Si} / \mathrm{SiGe}$ material system widely integrated into bipolar technology [1], [2]. Sales of $\mathrm{Si} / \mathrm{SiGe}$ bipolar/BiCMOS technologies doubled in 2001 compared with sales in 2000, despite the overall decrease of $30 \%$ in the silicon semiconductor market [3]. The tremendous success of $\mathrm{Si} / \mathrm{SiGe}$ bipolar and BiCMOS technologies has resulted in the desire to expand the performance gains achievable by using $\mathrm{SiGe}$ and research is now focusing on obtaining enhanced CMOS devices by incorporating SiGe [4]. The $4.2 \%$ lattice mismatch between $\mathrm{Si}$ and $\mathrm{Ge}$ can be used to obtain strained layers, where electron (in $\mathrm{Si}$ under tension) and hole (in SiGe under compression) transport are improved [5]. The strained layers are generated by epitaxial growth on a substrate of differing alloy composition to the growing film. The larger atomic spacing of Ge compared with $\mathrm{Si}$ results in tensile strained $\mathrm{Si}$ when grown on a relaxed SiGe virtual substrate (VS). In order to achieve compressively

Manuscript received January 29, 2003; revised May 19, 2003. This work was supported by a grant from EPSRC. The review of this paper was arranged by Editor R. Shrivastava.

S. H. Olsen, A. G. O’Neill, L. S. Driscoll, K. S. K. Kwa, and S. Chattopadhyay are with the School of Electrical, Electronic and Computer Engineering, Newcastle University, Newcastle, NE1 7RU U.K.

A. M. Waite, Y. T. Tang, and A. G. R. Evans are with the Department of Electronics and Computer Science, Southampton University, Southampton, SO17 1BJ U.K.

D. J. Norris and A. G. Cullis are with the Department of Electronic and Electrical Engineering, Sheffield University, Sheffield, S1 3JD U.K.

D. J. Paul is with the Cavendish Laboratory, University of Cambridge, Cambridge, CB3 OHE U.K

D. J. Robbins is with QinetiQ, Malvern, WR14 3PS U.K.

Digital Object Identifier 10.1109/TED.2003.815603 strained $\mathrm{SiGe}$, growth may either be on unstrained $\mathrm{Si}$ or a SiGe VS of lower alloy composition than the strained SiGe layer [6]. Modification to the electronic band structure and a reduced in-plane effective mass enhances hole mobility in compressively strained $\mathrm{SiGe}$ compared with unstrained $\mathrm{Si}$. Enhanced electron mobility is achieved in tensile strained $\mathrm{Si}$ through reduced intervalley scattering and a reduction in the in-plane effective mass. By fabricating MOSFET devices on the strained $\mathrm{Si} / \mathrm{SiGe}$ layers, faster CMOS devices and performance enhancements are predicted without the high costs associated with aggressive geometric scaling [4]. The enhanced mobility in strained $\mathrm{Si} / \mathrm{SiGe}$ devices compensates the reduction in mobility of conventional $\mathrm{Si}$ transistor channels as the gate insulator thickness is reduced [7]. Furthermore, the similarity of strained $\mathrm{Si} / \mathrm{SiGe}$ and conventional $\mathrm{Si}$ renders $\mathrm{SiGe}$ technology a relatively inexpensive choice for attaining high performance CMOS. Consequently, $\mathrm{Si} / \mathrm{SiGe} \mathrm{MOS}$ has been included as a key emerging research technology in the 2001 International Technology Roadmap for Semiconductors [8].

The development of $\mathrm{Si} / \mathrm{SiGe}$ FET technologies was initially hindered by the poor quality of relaxed SiGe virtual substrates. However, growth techniques have since improved dramatically and SiGe material with defect densities of $10^{5} \mathrm{~cm}^{-2}$ is now routinely available. Nevertheless, the demonstrated performance of strained $\mathrm{Si} / \mathrm{SiGe}$ MOS devices remains below theoretical expectations. The relatively low electrical performance of the $\mathrm{Si} / \mathrm{SiGe} \mathrm{MOS}$ devices is mainly attributed to the $\mathrm{Si} / \mathrm{SiGe}$ MOS process being modified to conserve the strained layers [9]. Strained layers may only be grown below a critical thickness $h_{c}$ before the strain relaxes. As well as losing the benefits of enhanced carrier transport, strain relaxation causes an introduction of misfit dislocations, which degrade device performance. The critical thickness decreases with increasing lattice mismatch between the strained layer and the substrate. However, strain and hence enhanced transport properties increase for higher values of lattice mismatch between the strained layer and underlying substrate [10], particularly for the p-channel and n-channels up to VS alloy compositions of approximately $\mathrm{Si}_{0.8} \mathrm{Ge}_{0.2}$. Therefore there is a clear limitation to the performance enhancement achievable in strained $\mathrm{Si} / \mathrm{SiGe}$ MOSFETs. Although it has been shown that a strained layer can be grown on a given alloy composition material to a thickness greater than $h_{c}$ without relaxation [11], so-called "metastable" material cannot withstand the high thermal budget processing commonly used in MOS fabrication. Consequently, most researchers have attempted fabrication of strained $\mathrm{Si} / \mathrm{SiGe}$ 


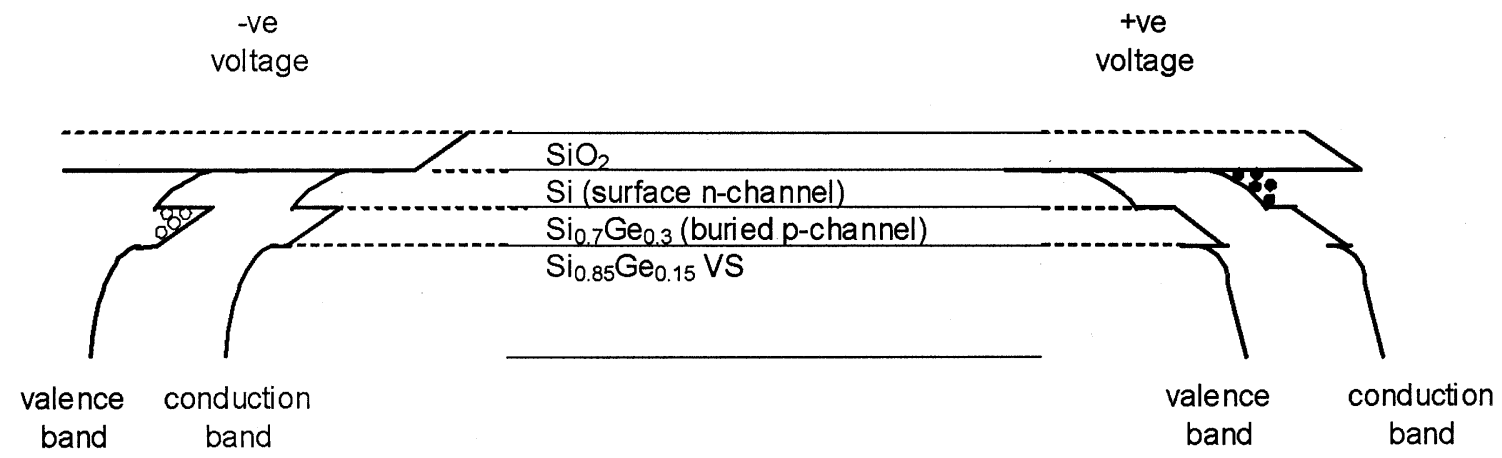

Fig. 1. Optimized CMOS architecture showing electrons in tensile strained $\mathrm{Si}$ and holes in compressively strained $\mathrm{Si}_{0.7} \mathrm{Ge}_{0.3}$ under inversion conditions.

MOSFETs using reduced thermal budgets and/or by lowering the alloy compositions, ultimately sacrificing the performance gains achievable [12]-[14].

In addition, all $\mathrm{Si} / \mathrm{SiGe}$ devices reported to date have epitaxially grown $\mathrm{Si} / \mathrm{SiGe}$ layers designed to maximize the performance of either n- or p-channel devices. Advanced CMOS, however, requires high performance from both $\mathrm{n}$ - and $\mathrm{p}$-channel devices. In the present study, by using a layer structure which does not compromise the performance of either n- or $\mathrm{p}$-channel devices, coupled with conventional MOS fabrication, high-performance strained silicon nMOSFETs are demonstrated, with maximum performance benefits predicted for $\mathrm{p}$-channel devices using the same VS [15]. Consequently a new route is presented for obtaining high-performance CMOS. The layer structure is additionally designed such that strain-compensation occurs between the n- and p-channels, and with strained channel thicknesses sufficient to allow conventional surface cleans and oxidation necessary for high-performance CMOS. The performance of the strained Si nMOSFETs presented in this paper exceeds that of recently reported devices [16] and is significantly enhanced compared with unstrained Si control devices over a wide range of gate lengths; our increases in drain current $\left(\mathrm{I}_{\mathrm{d}}\right)$ and transconductance $\left(\mathrm{g}_{\mathrm{m}}\right)$ are the highest reported to date. Furthermore, the performance gains are achieved without VS polishing thus the present technology is more compatible with conventional Si technology. The novel design used in the current study has therefore overcome the usual trade-off encountered in $\mathrm{Si} / \mathrm{SiGe}$ MOS technology between performance gains achievable (due to strain and consequently alloy composition) and thermal budget, while proving the most compatible $\mathrm{n}$ - and $\mathrm{p}$-channel device architecture suitable for advanced mainstream CMOS applications to date.

\section{DEVICE DESIGN AND FABRICATION}

The epitaxial layer structure of the strained $\mathrm{Si} / \mathrm{SiGe}$ devices is shown schematically in Fig. 1 . The strained $\mathrm{Si} / \mathrm{Si}_{0.7} \mathrm{Ge}_{0.3}$ channel layers are grown on a relaxed constant composition $\mathrm{Si}_{0.85} \mathrm{Ge}_{0.15} \mathrm{VS}$. By growing a $\mathrm{Si}_{0.7} \mathrm{Ge}_{0.3}$ layer on the VS, the higher Ge content alloy layer is compressively strained, making the layer ideal for a p-channel of high-mobility holes in a MOS device [15]. The smaller lattice constant of Si dictates that the subsequent Si layer (Fig. 1) is in tension, allowing electron mobility enhancement suitable for the n-channel of strained Si nMOSFETs. Furthermore, the band offsets between

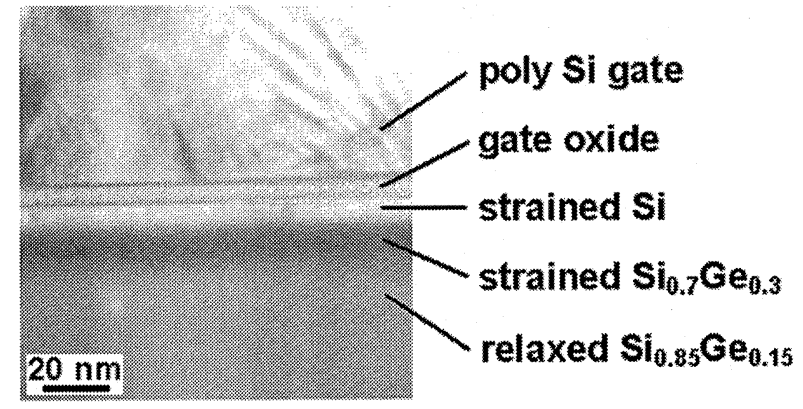

Fig. 2. High-resolution TEM image of the gate oxide and the strained $\mathrm{Si} / \mathrm{Si}_{0.3} \mathrm{Ge}_{0.3}$ layers on the relaxed $\mathrm{Si}_{0.85} \mathrm{Ge}_{0.15} \mathrm{VS}$.

the strained $\mathrm{Si}$ and $\mathrm{Si}_{0.7} \mathrm{Ge}_{0.3}$ layers enable the confinement of holes in the buried $\mathrm{Si}_{0.7} \mathrm{Ge}_{0.3}$ layer under negative bias conditions and a layer of electrons at the surface of the strained $\mathrm{Si}$ when a positive bias is applied to the MOS gate (Fig. 1). Thus, the present design describes a high-performance CMOS architecture incorporating a surface n-channel and buried p-channel. Following selective etching to remove some of the strained Si material (i.e., the n-channel) above the buried p-channel in order to increase the pMOSFET device transconductance, maximum performance is predicted from both nand p-channel devices on the single VS architecture [15]. The sequence of $\mathrm{SiGe}$ under compression and $\mathrm{Si}$ in tension creates a strain-compensated structure, minimizing cumulative strain in the devices. Transmission electron microscopy (TEM) analysis of the epitaxial layers following processing verified that the final tensile strained Si surface channel was approximately 7 nm (Fig. 2). The compressively strained $\mathrm{Si}_{0.7} \mathrm{Ge}_{0.3}$ layer was measured as $12 \mathrm{~nm}$. The n-channel (strained $\mathrm{Si}$ ) was intended to be slightly thicker than measured, and since the strained $\mathrm{Si}_{0.7} \mathrm{Ge}_{0.3}$ layer was slightly thicker than anticipated, it is likely that smearing of the heteroboundaries due to the high thermal budget process (below) may have caused the slight deviation from layer specification. Nevertheless, both the strained $\mathrm{Si}$ n-channel and strained $\mathrm{Si}_{0.7} \mathrm{Ge}_{0.3}$ p-channel were above the minimum thickness required to achieve maximum performance gains [17].

The $\mathrm{Si} / \mathrm{SiGe}$ layers were grown by low-pressure chemical vapor deposition in an Applied Materials Centura tool using $\mathrm{SiH}_{4}$ and $\mathrm{GeH}_{4}$ in a $\mathrm{H}_{2}$ carrier gas with $\mathrm{B}_{2} \mathrm{H}_{6}$ for $\mathrm{p}$-type doping [18], [19]. The 1- $\mu \mathrm{m}$ constant composition $\mathrm{Si}_{0.85} \mathrm{Ge}_{0.15} \mathrm{VS}$ and the preceding graded $\mathrm{Si}_{1-\mathrm{x}} \mathrm{Ge}_{\mathrm{x}}$ layer ( $\mathrm{x}=0$ to 0.15 ) were 


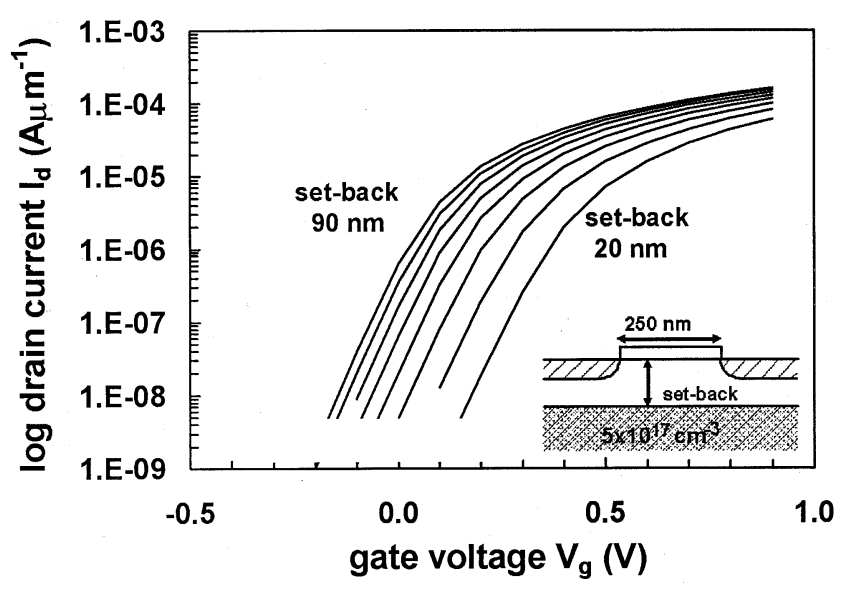

(a)

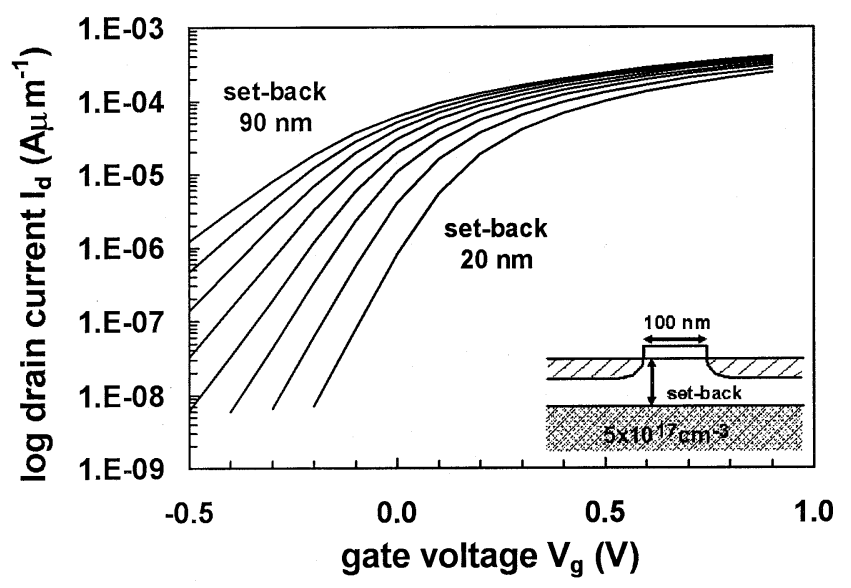

(b)

Fig. 3. Simulated dependence of subthreshold characteristics on background doping set-back layer thickness at $\mathrm{V}_{\mathrm{d}}=1.0 \mathrm{~V}$ for (a) 100 -nm and (b) $250-\mathrm{nm}$ gate length devices. The set-back layer thickness ranges from $20-90 \mathrm{~nm}$ in steps of $10 \mathrm{~nm}$.

grown above $800{ }^{\circ} \mathrm{C}$ in order to promote misfit dislocation nucleation and propagation [20]. The strained $\mathrm{Si} / \mathrm{Si}_{0.7} \mathrm{Ge}_{0.3}$ layers were subsequently grown at reduced temperature for maximum control of layer thickness and Ge segregation. Secondary ion mass spectroscopy, x-ray diffraction, and Raman spectroscopy were used to confirm the as-grown layer thickness, alloy composition and strain of a strained Si layer grown directly on a $\mathrm{Si}_{0.85} \mathrm{Ge}_{0.15}$ VS at the same time as the device wafers.

Drift-diffusion technology computer aided design (TCAD) simulations were carried out in Medici [21] in order to determine a suitable as-grown B profile for the devices. Fig. 3 shows the simulated variation of subthreshold characteristics with substrate doping $\left(\mathrm{N}_{\mathrm{a}}\right)$ set-back layer thickness (the separation between the substrate doping and the strained Si surface channel) for MOSFETs with a $6 \mathrm{~nm}$ gate oxide. The characteristics were investigated for set-back layer thicknesses ranging from 20-90 $\mathrm{nm}$ in 10-nm intervals. The data is simulated at a drain voltage $\left(\mathrm{V}_{\mathrm{d}}\right)$ of $1.0 \mathrm{~V}$ and suggests that a final set-back layer thickness of approximately $50 \mathrm{~nm}$ between a $5 \times 10^{17} \mathrm{~cm}^{-3}$ (B) diffusion edge and the strained Si surface channel would enable good subthreshold characteristics for $0.25-\mu \mathrm{m}$ gate length devices [Fig. 3(a)], while a greater dependence of set-back layer thickness is observed for 100-nm gate length devices [Fig. 3(b)].

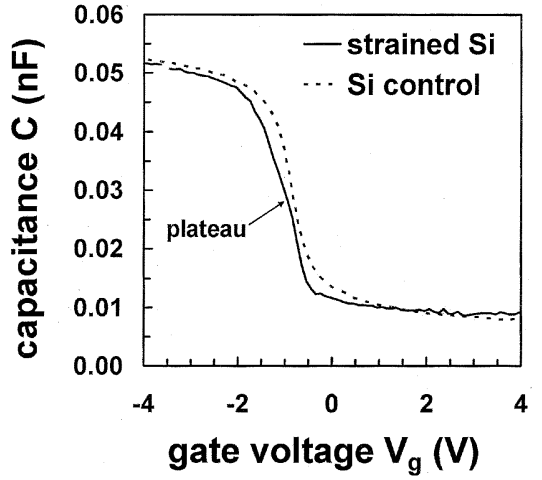

Fig. 4. $C-V$ characteristics of $100 \mu \mathrm{m} \times 100 \mu \mathrm{m}$ MOS capacitors on strained $\mathrm{Si} / \mathrm{SiGe}$ and control device wafers. The similarity of the strained $\mathrm{Si} / \mathrm{SiGe}$ accumulation capacitance and the $\mathrm{Si}$ control accumulation capacitance indicates equivalent gate oxide thickness of the devices.

The channel doping was taken to be $1 \times 10^{16} \mathrm{~cm}^{-3}$ in order to maintain high carrier mobility. An allowance of $25 \mathrm{~nm}$ was incorporated into the initial set-back layer thickness based on simulations of B diffusion during thermal processing [22]. Diffusion coefficients for B in SiGe were adapted from [23], [24] and all processing steps carried out at temperatures greater than $400{ }^{\circ} \mathrm{C}$ were included in the simulation.

The Si/SiGe wafers did not require chemical-mechanical polishing (CMP), since the as-grown rms roughness of the VS was low, at $1.3 \mathrm{~nm}$, as measured by AFM and optical profilometry on $25 \mu \mathrm{m} \times 25 \mu \mathrm{m}$ areas around the wafer. This is one of the lowest roughness values reported for as-grown $\mathrm{Si}_{0.85} \mathrm{Ge}_{0.15} \mathrm{VS}$ material to date. Device fabrication mainly followed standard $0.25-\mu \mathrm{m}$ CMOS processing. Active areas were defined in deposited oxide and dry thermal oxidation at $800{ }^{\circ} \mathrm{C}$ followed by a $\mathrm{N}_{2}$ anneal produced a 6-nm gate oxide, measured by capacitance-voltage $(C-V)$ profiling on MOS capacitors fabricated on the device wafers and by TEM (Fig. 2). Representative $C-V$ characteristics of $100 \mu \mathrm{m} \times 100 \mu \mathrm{m}$ MOS capacitors are shown in Fig. 4. The similarity of the two accumulation capacitances indicates that the oxide thickness of the strained $\mathrm{Si} / \mathrm{SiGe}$ wafer is equivalent to that of the control wafer. The small plateau in capacitance observed on the strained $\mathrm{Si} / \mathrm{SiGe} \mathrm{MOS}$ capacitor at approximately $-1 \mathrm{~V}$ is due to the confinement of holes in the $\mathrm{Si}_{0.3} \mathrm{Ge}_{0.7}$ layer [25]. Fig. 5 shows the interface trap density $\left(\mathrm{D}_{\mathrm{it}}\right)$ as a function of bandgap energy measured using a quasistatic $C-V$ technique [26]. $\mathrm{D}_{\text {it }}$ at mid-gap was found to be approximately $6 \times 10^{10} \mathrm{~cm}^{-2} \mathrm{eV}^{-1}$ for both capacitors, confirming that the $\mathrm{Si} / \mathrm{SiO}_{2}$ interface quality of the strained $\mathrm{Si} / \mathrm{SiGe}$ devices was similar to the control devices. The small discrepancy in the gate oxide thickness measured by TEM $(6 \mathrm{~nm})$ and the electrical oxide thickness measured by $C-V(6.5 \mathrm{~nm})$ is due to quantum mechanical and polysilicon depletion effects [27]. Electron beam lithography defined polysilicon gate lengths (L) down to $150 \mathrm{~nm}$ and As implants annealed at $1050{ }^{\circ} \mathrm{C}$ for 20 $\mathrm{s}$ created the source and drain. Duplicate $\mathrm{Si} / \mathrm{SiGe}$ and control $\mathrm{Si}$ wafers additionally underwent a salicide process split using $\mathrm{Si}_{3} \mathrm{~N}_{4}$ side-wall spacers and $\mathrm{TiSi}_{2}$. A bright-field TEM image of a typical silicided strained $\mathrm{Si} / \mathrm{SiGe}$ device structure is shown in Fig. 6. The silicide was found to reduce the sheet resistance of the $\mathrm{Si} / \mathrm{SiGe}$ source and drain regions from $68 \Omega /$ sq to below 


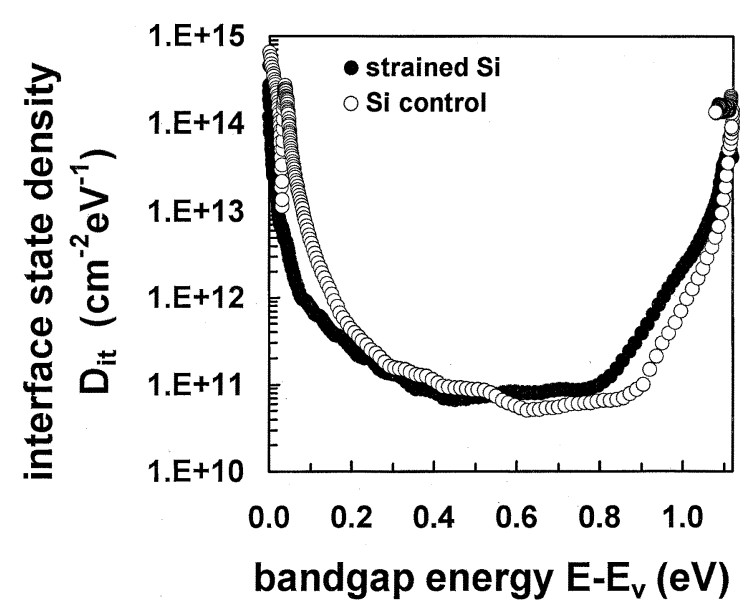

Fig. 5. Interface trap density $\left(D_{i t}\right)$ versus bandgap energy for a strained $\mathrm{Si} / \mathrm{SiGe}$ and $\mathrm{Si}$ control MOS capacitors indicating equivalent mid-band $\mathrm{D}_{\mathrm{it}}$ values.

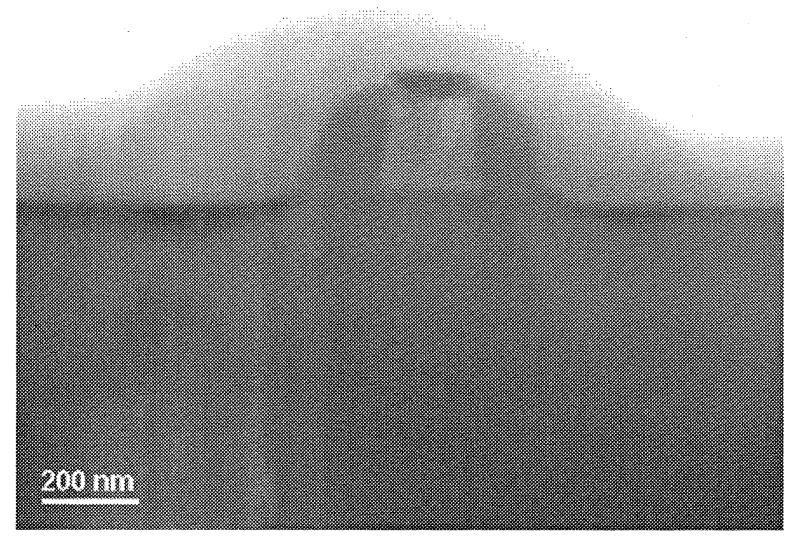

Fig. 6. Bright-field TEM image of a 150-nm drawn gate length strained $\mathrm{Si} / \mathrm{SiGe}$ device structure.

$8 \Omega /$ sq, as measured on standard Van der Pauw structures on the device wafers.

\section{Device Results}

The nMOSFETs exhibited excellent subthreshold characteristics. Fig. 7 shows the transfer characteristics of a $0.3-\mu \mathrm{m}(\mathrm{L})$ silicided strained Si device at $\mathrm{V}_{\mathrm{d}}=0.1 \mathrm{~V}$ and $1.0 \mathrm{~V}$. The nMOSFET gate width (W) is $5 \mu \mathrm{m}$. $\mathrm{V}_{\mathrm{g}}$ is the applied gate voltage and $V_{t}$ is the device threshold voltage. There is a ten order of magnitude difference between the on-state drain current $\left(\mathrm{I}_{\text {on }}\right)$ and the off-state drain current $\left(\mathrm{I}_{\text {off }}\right)$ and the subthreshold slope is $80 \mathrm{mV} / \mathrm{dec}$. Drain-induced barrier lowering (DIBL) was found to be below $10 \mathrm{mV} / \mathrm{V}$ and equal to the control devices over a wide range of gate lengths (Fig. 8). $\mathrm{V}_{\mathrm{t}}$ as a function of $\mathrm{L}$ for the devices is shown in Fig. 9 and the steepness of the roll-off characteristics for the strained $\mathrm{Si} / \mathrm{SiGe}$ devices are also found to be similar to those of the Si control devices. Enhanced diffusion of As in SiGe compared with that in bulk Si may cause the slightly earlier roll-off observed for the strained Si/SiGe MOSFETs compared with the $\mathrm{Si}$ controls. $C-V$ profiling of MOS capacitors on the $\mathrm{Si} / \mathrm{SiGe}$ and $\mathrm{Si}$ control device wafers confirmed that $\mathrm{N}_{\mathrm{a}}$ of the $\mathrm{Si} / \mathrm{SiGe}$ wafer was equivalent to that of the $\mathrm{Si}$ control wafers. Therefore, the lower $V_{t}$ values observed for the

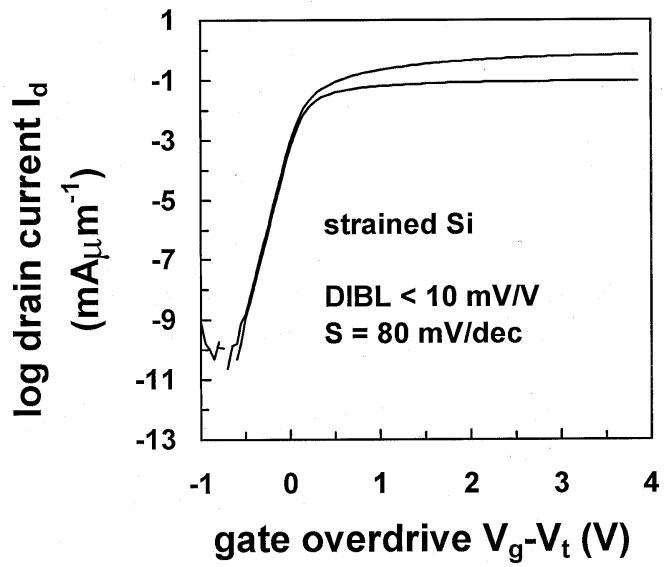

Fig. 7. Typical $\log I_{d}$ versus $V_{g}-V_{t}$ characteristics for a $0.3 \mu \mathrm{m}(\mathrm{L}) \times 5 \mu \mathrm{m}$ (W) silicided strained Si device at $\mathrm{V}_{\mathrm{d}}=0.1 \mathrm{~V}$ and $1.0 \mathrm{~V}$. $\mathrm{I}_{\mathrm{on}} / \mathrm{I}_{\text {off }}$ exceeds ten orders of magnitude.

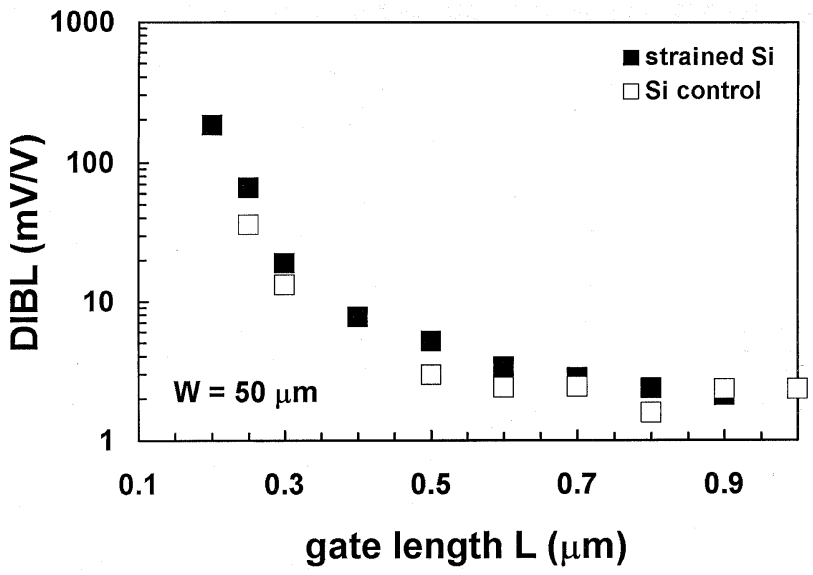

Fig. 8. DIBL as a function of gate length for silicided devices. Similar electrostatic integrity of strained $\mathrm{Si}$ and control devices is achieved at all gate lengths.

strained $\mathrm{Si} / \mathrm{SiGe}$ device are mainly attributed to the differing electron affinities of the materials [16], [28].

The variation of transconductance $\mathrm{g}_{\mathrm{m}}$ with gate overdrive, $\mathrm{V}_{\mathrm{g}}-\mathrm{V}_{\mathrm{t}}$, for $0.2 \mu \mathrm{m}(\mathrm{L}) \times 5 \mu \mathrm{m}(\mathrm{W})$ silicided strained $\mathrm{Si}$ and $\mathrm{Si}$ control devices is presented in Fig. 10. The maximum $\mathrm{g}_{\mathrm{m}}$ $\left(\mathrm{g}_{\mathrm{m}}^{\max }\right)$ of the strained Si device is $334 \mathrm{mSmm}^{-1}$ and is enhanced by $50 \%$ compared with the $\mathrm{Si}$ control device at $\mathrm{V}_{\mathrm{d}}=1.0$ V. Fig. 11 shows output characteristics of unsilicided $0.3 \mu \mathrm{m}$ $(\mathrm{L}) \times 5 \mu \mathrm{m}(\mathrm{W})$ devices. Large increases in $\mathrm{I}_{\mathrm{d}}$ of the strained Si device compared with the control device are observed despite d.c. self-heating at higher $\mathrm{V}_{\mathrm{d}}$, evident as the negative gradient in the curves. The self-heating of the strained $\mathrm{Si} / \mathrm{SiGe}$ devices arises from the lower thermal conductivity of SiGe compared with Si [29] and results in a significantly elevated channel temperature [30]. Nevertheless, $I_{d}$ of the strained Si nMOSFETs is substantially higher than recently reported strained $\mathrm{Si}$ devices with a similar geometry and subthreshold characteristics [16]. This is in spite of our devices having an increase in gate oxide thickness of $50 \%$ and characteristics measured without using an a.c. conductance technique to remove the effect of self-heating. At $\mathrm{V}_{\mathrm{d}}=1.5 \mathrm{~V}$ and $\mathrm{V}_{\mathrm{g}}-\mathrm{V}_{\mathrm{t}}=1.5 \mathrm{~V}, \mathrm{I}_{\mathrm{d}}$ of the 


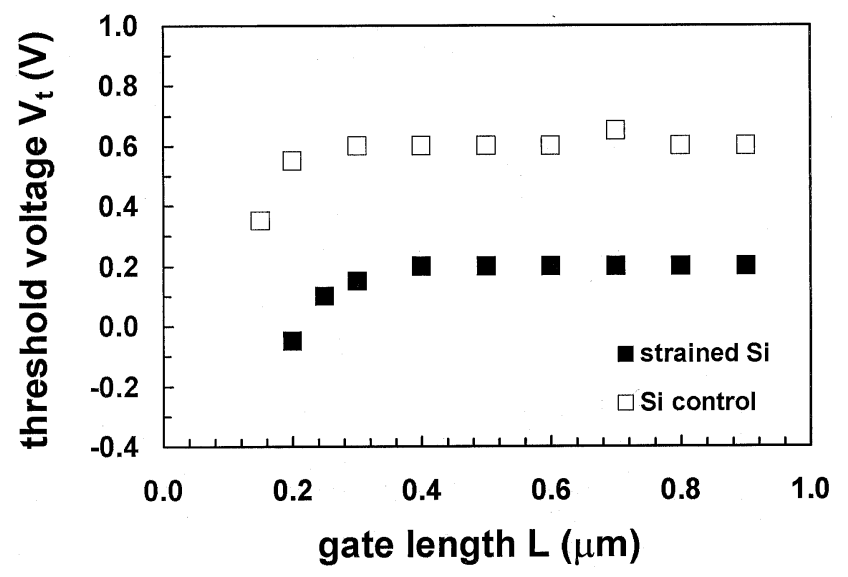

Fig. 9. $\quad V_{t}$ as a function of $\mathrm{L}$ for the strained $\mathrm{Si}$ and $\mathrm{Si}$ control devices.

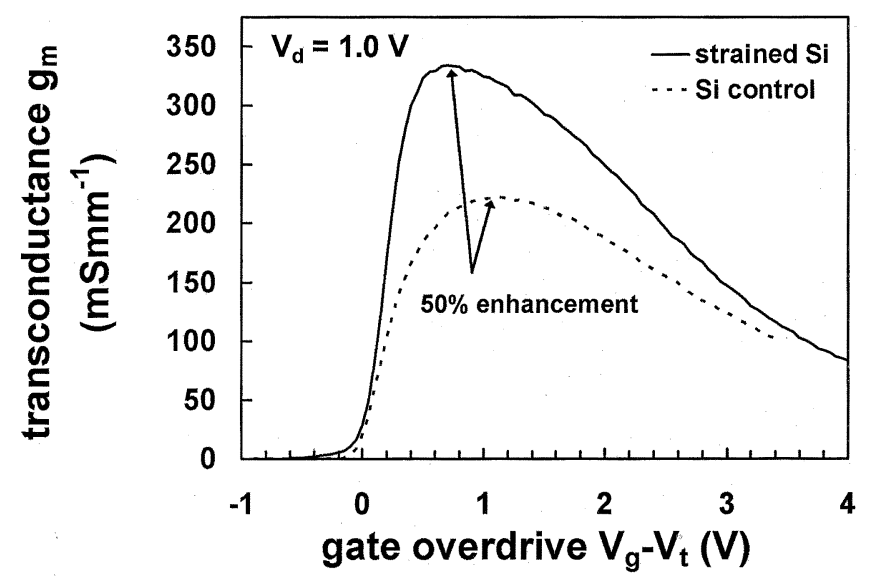

Fig. 10. $g_{m}$ versus $V_{g}-V_{t}$ curves for $0.2 \mu \mathrm{m}(\mathrm{L}) \times 5 \mu \mathrm{m}(\mathrm{W})$ silicided strained $\mathrm{Si}$ and $\mathrm{Si}$ control devices at $\mathrm{V}_{\mathrm{d}}=1.0 \mathrm{~V}$. The strained $\mathrm{Si}$ device exhibits an increase in $\mathrm{g}_{\mathrm{m}}^{\max }$ of $50 \%$ compared with the control device.

strained Si device is approximately $0.55 \mathrm{~mA} \mu \mathrm{m}^{-1}$ and is increased by over $140 \%$ compared with the Si control device, exceeding recently published data [14], [16], [31], [32]. Moreover, unlike the strained Si devices reported in [16] and [31], the excellent performance of our devices is achieved without requiring any CMP stages. Therefore, our SiGe MOS technology provides an improved cost-effective solution to Moore's Law. The higher performance of our strained $\mathrm{Si} / \mathrm{SiGe}$ nMOSFETs is attributed to full thermal budget processing and simultaneously achieving optimum channel thickness and strain conditions through use of a relatively low alloy composition VS. In addition, the strained $\mathrm{Si} / \mathrm{SiGe}$ material exhibited a very low defect density. Schimmel etching was carried out and the threading dislocation density was found to be approximately $2 \times 10^{4} \mathrm{~cm}^{-2}$. Consequently the probability of such defects degrading electrical performance is small. Simulations show that the high alloy content strain compensation layer will also allow maximum performance advantages from p-channel devices [15]. Thus, the novel design and fabrication process described have overcome the usual performance trade-off encountered in strained $\mathrm{Si} / \mathrm{SiGe}$ MOS technology arising from the critical thickness, while demonstrating the most compatible architecture suitable for advanced CMOS performance to date.

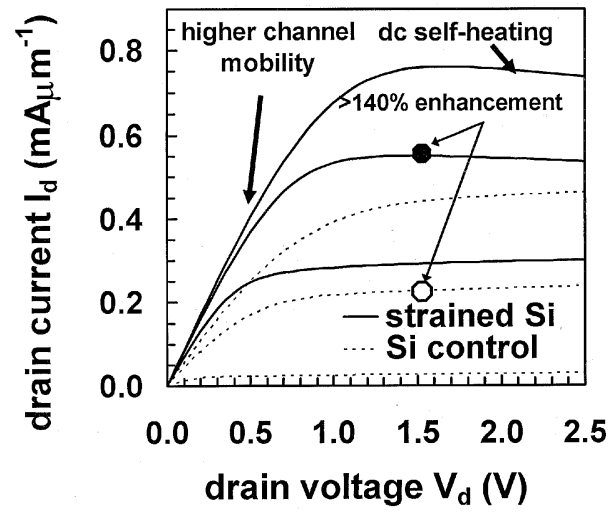

Fig. 11. $I_{d}$ versus $V_{d}$ characteristics of unsilicided $0.3 \mu \mathrm{m}(\mathrm{L}) \times 5 \mu \mathrm{m}(\mathrm{W})$ devices in $\mathrm{V}_{\mathrm{g}}-\mathrm{V}_{\mathrm{t}}$ steps of $1.0 \mathrm{~V}$ from $0.5 \mathrm{~V}$ to $2.5 \mathrm{~V}$. Current drive of the strained Si device is increased by over $140 \%$ compared with the Si control device at $\mathrm{V}_{\mathrm{d}}=1.5 \mathrm{~V}, \mathrm{~V}_{\mathrm{g}}-\mathrm{V}_{\mathrm{t}}=1.5 \mathrm{~V}$ despite evidence of self-heating.

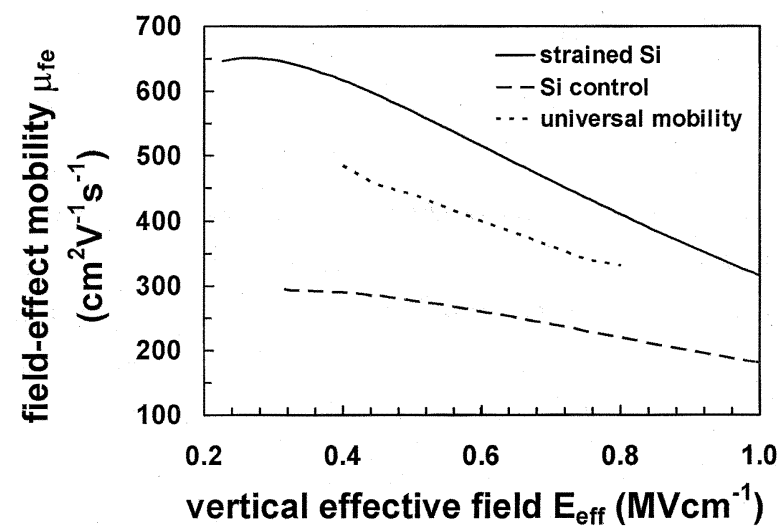

Fig. 12. Field-effect mobility $\mu_{\mathrm{fe}}$ versus effective electric field $\mathrm{E}_{\mathrm{eff}}$ measured at $\mathrm{V}_{\mathrm{d}}=0.1 \mathrm{~V}$.

The higher mobility of the strained Si MOSFET channel is indicated by the early saturation in Fig. 11. This was confirmed by examining the field-effect mobility $\mu_{\mathrm{fe}}$ [33] on large (10 $\mu \mathrm{m})$ gate length devices as a function of effective field $\mathrm{E}_{\text {eff }}$ at $\mathrm{V}_{\mathrm{d}}=0.1 \mathrm{~V}$ (Fig. 12). The peak $\mu_{\mathrm{fe}}$ was found to be 650 $\mathrm{cm}^{2} \mathrm{~V}^{-1} \mathrm{~s}^{-1}$ for the strained Si devices, increased by over $120 \%$ compared with the Si control device and equivalent to the highest reported electron mobility enhancement in strained Si surface channel MOSFETS to date [16]. In addition, the peak $\mu_{\mathrm{fe}}$ of the strained $\mathrm{Si}$ is greater than recently reported high-performance devices [32]. Moreover, our mobility data refers to field-effect mobility $\mu_{\mathrm{fe}}$, whereas commonly reported effective mobility $\left(\mu_{\text {eff }}\right)$ inflates mobility values by up to $25 \%$, particularly at high vertical fields [33]. Nevertheless, Fig. 12 shows that strained Si mobility enhancements exceeding $100 \%$ compared with the control devices are achieved at vertical fields above $0.6 \mathrm{MVcm}^{-1}$, suitable for sub-100-nm devices. Significant mobility enhancements over the universal mobility curve are also achieved throughout the $\mathrm{E}_{\text {eff }}$ range investigated. The deviation observed between the $\mathrm{Si}$ control data and the universal mobility data is considered to primarily arise from the $\mathrm{Si}$ control devices being fabricated directly on bulk Czochralski-grown $\mathrm{Si}$, which exhibits poor material quality compared with epitaxially grown $\mathrm{Si}$. In addition, unlike field-effect mobility data, universal mobility data refers to 


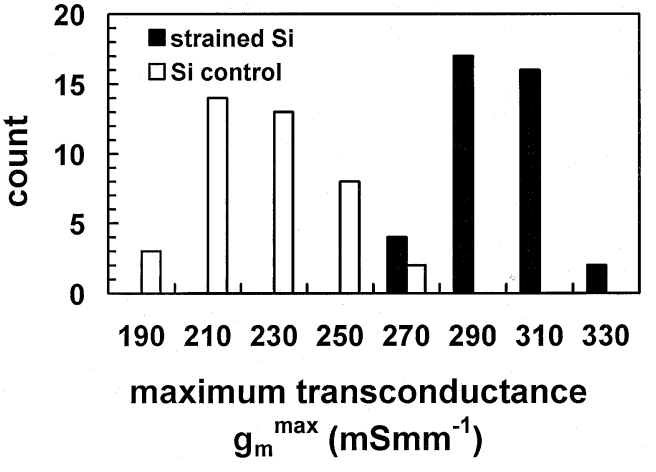

Fig. 13. Comparison of the variation in $\mathrm{g}_{\mathrm{m}}^{\max }$ of all $0.3 \mu \mathrm{m}$ (L) $\times 5 \mu \mathrm{m}$ (W) strained $\mathrm{Si} / \mathrm{SiGe}$ and $\mathrm{Si}$ control devices. The nMOSFETs are unsilicided and the measurements were carried out at $\mathrm{V}_{\mathrm{d}}=1.0 \mathrm{~V}$. The standard deviation of the mean value of $\mathrm{g}_{\mathrm{m}}^{\max }$ was equivalent for both sets of devices, highlighting the excellent $\mathrm{Si} / \mathrm{SiGe}$ material uniformity.

effective mobility, which takes into account the degradation to mobility due to the vertical field [33].

Excellent uniformity of the strained Si nMOSFET performance was determined by device measurements on all die on the wafers. A histogram comparing the variation in $\mathrm{g}_{\mathrm{m}}^{\max }$ for $0.3 \mu \mathrm{m}(\mathrm{L}) \times 5 \mu \mathrm{m}(\mathrm{W})$ strained $\mathrm{Si}$ and control devices at $\mathrm{V}_{\mathrm{d}}=1.0 \mathrm{~V}$ is shown in Fig. 13. The standard deviation of the mean value of $\mathrm{g}_{\mathrm{m}}^{\max }$ for the strained Si devices was less than 5\% and within experimental error of the deviation in $\mathrm{g}_{\mathrm{m}}^{\max }$ of the control devices. The high degree of electrical uniformity exhibited by the nMOSFETs is attributed to the uniform $\mathrm{Si} / \mathrm{SiGe}$ material and demonstrates its suitability for commercial manufacture; equivalent conventional $\mathrm{Si}$ industrial processes currently run with similar deviations in device gain [34]. The superior $g_{m}$ as well as $\mu_{\mathrm{fe}}$ of the strained $\mathrm{Si} / \mathrm{SiGe}$ devices verifies successful layer design and fabrication as well as material quality.

The higher performance of the strained $\mathrm{Si} / \mathrm{SiGe}$ nMOSFETs at $\mathrm{V}_{\mathrm{d}}=1.0 \mathrm{~V}$ was consistently observed at all gate lengths investigated, as shown in Fig. 14. The relative performance of the strained Si devices and the Si controls is shown in Fig. 15. At $\mathrm{V}_{\mathrm{d}}=0.1 \mathrm{~V}$ the enhancement in $\mathrm{g}_{\mathrm{m}}^{\max }$ of the strained Si devices is greater at smaller gate lengths. Performance gains in $\mathrm{g}_{\mathrm{m}}^{\max }$ (extrinsic) exceeding $170 \%$ are clearly demonstrated. These are the highest room temperature enhancements in $\mathrm{g}_{\mathrm{m}}^{\max }$ of strained $\mathrm{Si} / \mathrm{SiGe}$ surface channel nMOSFETs reported to date. The exceptional performance is shown for both silicided and unsilicided devices and indicates the success of the $\mathrm{TiSi}_{2}$ process on strained $\mathrm{Si} / \mathrm{SiGe}$ material. Furthermore, Fig. 8 shows that the improved performance does not compromise electrostatic integrity. As $V_{d}$ is increased, transconductance enhancements of strained $\mathrm{Si}$ devices are reduced for all $\mathrm{L}$, and in particular at shorter $\mathrm{L}$; at $\mathrm{V}_{\mathrm{d}}=1.2 \mathrm{~V}$ the enhancement is reduced to below $50 \%$ for $\mathrm{L}<0.6 \mu \mathrm{m}$.

The impact of device self-heating due to the low thermal conductivity of SiGe was investigated by measuring $\mathrm{I}_{\mathrm{d}} / \mathrm{W}$ for devices with a range of gate widths $(\mathrm{W})$ while maintaining a constant field parallel to the device channel. The results for $0.3-\mu \mathrm{m}$ (L) devices at $\mathrm{V}_{\mathrm{d}}=1.0 \mathrm{~V}$ are shown in Fig. 16. The greater deviation from ideal saturation characteristics observed for larger gate width devices is due to the generation of higher currents in these devices, verifying that the degraded performance en-

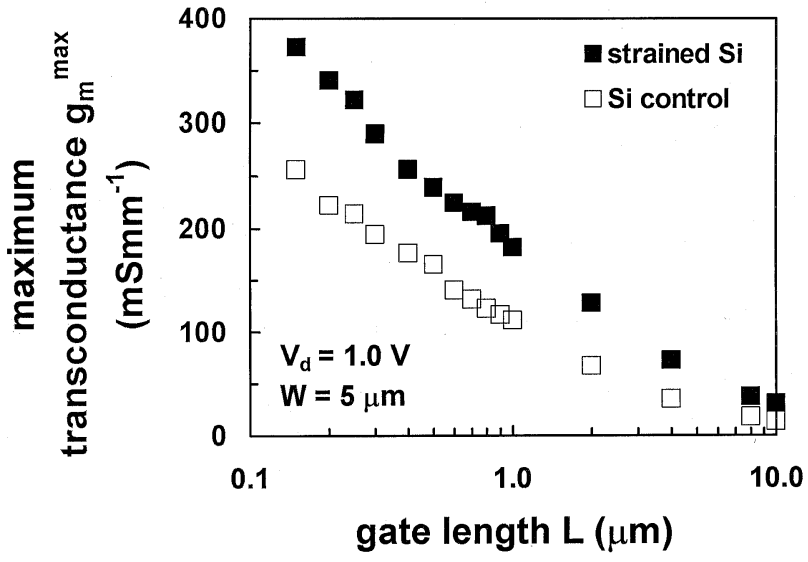

Fig. 14. $\mathrm{g}_{\mathrm{m}}^{\max }$ versus $\mathrm{L}$ for silicided devices at $\mathrm{V}_{\mathrm{d}}=1.0 \mathrm{~V}$. Intrinsic values of $\mathrm{g}_{\mathrm{m}}^{\max }$ are shown. Large performance gains are achieved at all gate lengths.

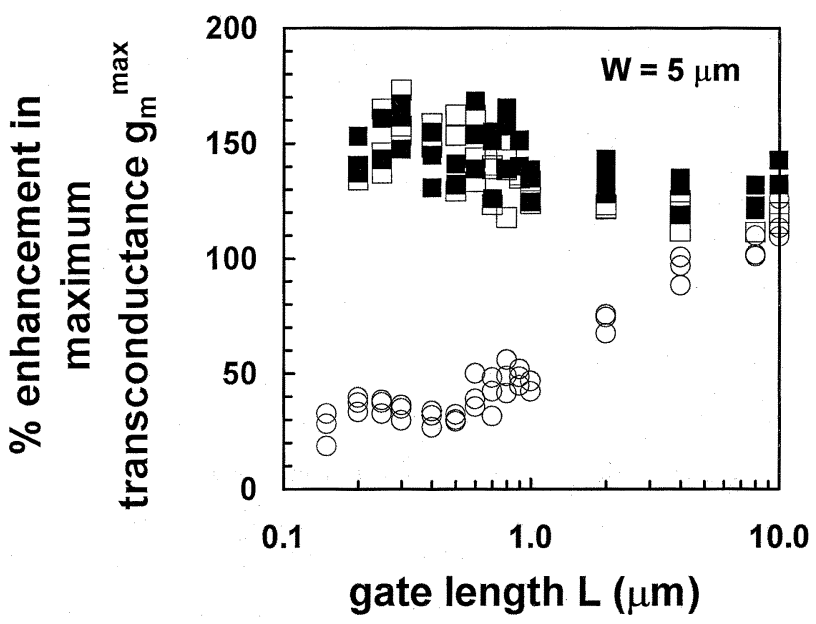

Fig. 15. Percentage enhancement in strained $\mathrm{Si} \mathrm{g}_{\mathrm{m}}^{\max }$ (extrinsic) compared with $\mathrm{Si}$ control devices as a function of gate length. $\mathrm{V}_{\mathrm{d}}=0.1 \mathrm{~V}$ (silicided); $\square \mathrm{V}_{\mathrm{d}}=0.1 \mathrm{~V}$ (unsilicided); $\bigcirc \mathrm{V}_{\mathrm{d}}=1.2 \mathrm{~V}$ (unsilicided). Peak performance gains exceeding $170 \%$ are demonstrated. Similar enhancements for silicided and unsilicided strained $\mathrm{Si}$ devices over all gate lengths indicate successful $\mathrm{Ti}$ silicidation of $\mathrm{Si} / \mathrm{SiGe}$ material. Self-heating causes reduced gains of strained $\mathrm{Si} / \mathrm{SiGe}$ devices at higher drive currents (small $\mathrm{L}$, high $\mathrm{V}_{\mathrm{d}}$ ).

hancement in devices producing high current densities is due to self-heating. Thus, the reduced enhancements in $\mathrm{g}_{\mathrm{m}}^{\max }$ observed at higher bias voltages and smaller L (Fig. 15) are due to SiGe self-heating effects dominating the gain available in strained $\mathrm{Si}$ devices producing high current levels rather than a result of earlier velocity saturation in strained Si compared with unstrained Si [35].

The degradation in mobility at high vertical fields is dominated by surface roughness scattering. However, high values of fixed oxide charge $\mathrm{Q}_{\mathrm{f}}$ may also degrade mobility over a wide range of $E_{\text {eff }}$ [33]. The Si control device exhibits a slightly slower decrease of mobility with $\mathrm{E}_{\mathrm{eff}}$ than observed for the strained Si device (Fig. 12). The greater dependence of $\mu_{\mathrm{fe}}$ on $\mathrm{E}_{\mathrm{eff}}$ for the strained Si device may be indicative of slightly higher gate oxide interface roughness than that of the control device. This may arise, for example, from Ge segregation from the SiGe layers into the Si channel leading to nonuniform oxidation rates [12] and consequently gate oxide interface roughness. Interference of Ge during gate oxidation additionally causes de- 


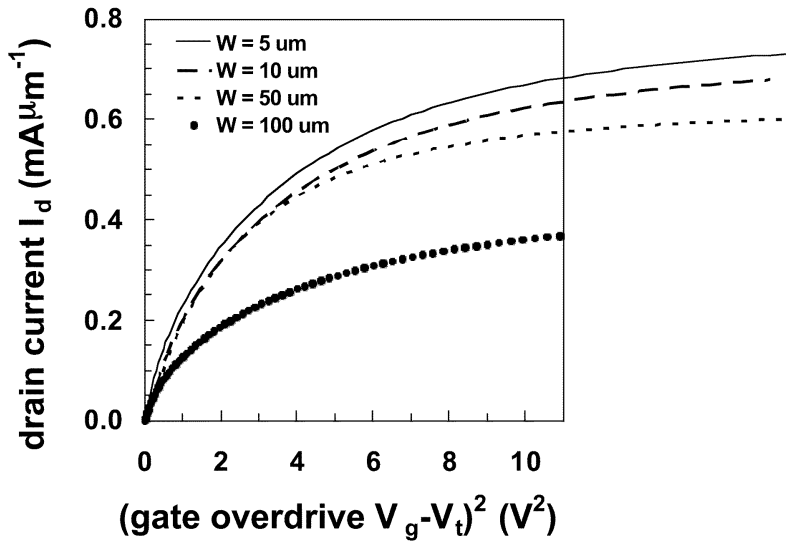

Fig. 16. Dependence of $I_{d}$ on $\left(V_{g}-V_{t}\right)^{2}$ for $0.3-\mu m$ strained $\mathrm{Si} / \mathrm{SiGe}$ devices as a function of $\mathrm{W}$ at $\mathrm{V}_{\mathrm{d}}=1.0 \mathrm{~V}$. The deviation from ideal device behavior increases for larger $\mathrm{W}$ devices due to the increased impact of self-heating.

graded electrical properties of oxides. However, $C-V$ measurements indicated that $D_{i t}$ for the strained Si devices was similar to that of the control device (Fig. 5) and therefore it is anticipated that $\mathrm{Q}_{\mathrm{f}}$ for both devices is also similar. Consequently the impact of Ge segregation on the electrical characteristics of devices in the current study is believed to be minor. Furthermore, little difference in the gate oxide/Si interface roughness between strained and unstrained $\mathrm{Si}$ is expected from $\mathrm{Si} / \mathrm{SiGe}$ material with such low values of cross-hatching roughness [36]. The slightly larger decrease in $\mu_{\mathrm{fe}}$ for the strained Si device at higher fields is therefore attributed to $\mu_{\mathrm{fe}}$ being derived from $I_{d}$, which has been shown to decrease due to self-heating at higher current levels and thus higher $E_{\text {eff }}$. At $V_{d}=0.1 \mathrm{~V}$ the effects are small (Fig. 15), in agreement with mobility data. However, at higher $\mathrm{V}_{\mathrm{d}}$ the reduced performance advantages due to self-heating are significant (see Figs. 15 and Fig. 16). Consequently, minimizing self-heating, for example by using pulsed a.c. measurements or reducing the VS thickness will result in even greater performance gains over a wider range of operating conditions.

\section{CONCLUSION}

High-performance nMOSFETs have been fabricated with an optimized strained $\mathrm{Si} / \mathrm{SiGe}$ channel. The layer structure incorporated a high Ge content strain compensation layer, which minimized the overall strain within the device. Electrical performance in terms of transconductance, field-effect mobility and on-state drain current was found to be enhanced by up to $170 \%$ compared with conventional MOSFETs, some of the highest gains reported to date, while excellent off-state leakage currents and subthreshold characteristics were maintained. The high performance has been attained without the use of CMP or pulsed measurements. No modifications to standard processing were necessary and the gain in silicided strained $\mathrm{Si} / \mathrm{SiGe}$ device performance was as great as in their unsilicided counterparts. The work suggests that pulsed measurements should be used for device measurements in order to assess the full potential of strained $\mathrm{Si} / \mathrm{SiGe}$ MOSFETs, since this is a more realistic reflection of device performance in switching circuits.

\section{ACKNOWLEDGMENT}

The authors would like to thank S. Bull for use of the AFM.

\section{REFERENCES}

[1] B. S. Meyerson, "Silicon: Germanium-based mixed-signal technology for optimization of wired and wireless telecommunications," IBM J. Res. Dev., vol. 44, no. 3, pp. 391-407, 2000.

[2] S. C. Jain, S. Decoutere, M. Willander, and H. E. Maes, "SiGe HBTs for applications in BiCMOS technology: I. Stability, reliability and material parameters," Semicond. Sci. Technol., vol. 16, pp. R51-R65, 2001.

[3] IC Insights, Inc.. [Online]. Available: www.icinsights.com.

[4] A. G. O'Neill and D. A. Antoniadis, "Deep submicron CMOS based on silicon germanium technology," IEEE Trans. Electron Devices, vol. 43, pp. 911-918, June 1996.

[5] M. V. Fischetti and S. E. Laux, "Band structure, deformation potentials, and carrier mobility in strained $\mathrm{Si}, \mathrm{Ge}$, and SiGe alloys," J. Appl. Phys., vol. 80, no. 4, pp. 2234-2252, 1996.

[6] D. J. Paul, "Silicon-germanium strained layer materials in microelectronics," Adv. Mater., vol. 11, no. 3, pp. 191-204, 1999.

[7] M. V. Fischetti, "Long-range Coulomb interactions in small Si devices. Part II. Effective electron mobility in thin-oxide structures," J. Appl. Phys., vol. 89, no. 2, pp. 1232-1250, 2001.

[8] 2001 International technology roadmap for semiconductors. [Online]. Available: http://public.itrs.net.

[9] J. W. Matthews and A. E. Blakeslee, "Defects in epitaxial multilayers," J. Cryst. Growth, vol. 27, pp. 118-125, 1974.

[10] J. Welser, J. L. Hoyt, S. Takagi, and J. F. Gibbons, "Strain dependence of the performance enhancement in strained-Si n-MOSFETs," in IEDM Tech. Dig., 1994, pp. 373-376.

[11] J. C. Bean, L. C. Feldman, A. T. Fiory, S. Nakahara, and I. K. Robinson, " $\mathrm{Ge}_{\mathrm{x}} \mathrm{Si}_{1-\mathrm{x}} / \mathrm{Si}$ strained-layer superlattice grown by molecular beam epitaxy," J. Vac. Sci. Technol. A, vol. 2, no. 2, pp. 436-440, 1984.

[12] S. H. Olsen et al., "Strained Si/SiGe n-channel MOSFETs: Impact of cross-hatching on device performance," Semicond. Sci. Technol., vol. 17 , pp. 655-661, 2002.

[13] A. G. O'Neill et al., "SiGe virtual substrate n-channel heterojunction MOSFETs," Semicond. Sci. Technol., vol. 14, pp. 784-789, 1999.

[14] K. Rim, J. L. Hoyt, and J. F. Gibbons, "Fabrication and analysis of deep submicron strained-Si n-MOSFETs," IEEE Trans. Electron Devices, vol. 47, pp. 1406-1415, July 2000.

[15] S. G. Badcock, A. G. O'Neill, and E. G. Chester, "Device and circuit performance of SiGe/Si MOSFETs," Solid-State Electron., vol. 46, no. 11, pp. 1925-1932, 2002.

[16] N. Sugii, D. Hisamoto, K. Washio, N. Yokoyama, and S. Kimura, "Enhanced performance of strained-Si MOSFETs on CMP SiGe virtual substrate," in IEDM Tech. Dig., 2001, pp. 737-740.

[17] M. T. Currie, C. W. Leitz, T. A. Langdo, G. Taraschi, and E. A. Fitzgerald, "Carrier mobilities and process stability of strained Si nand p-MOSFETs on SiGe virtual substrates," J. Vac. Sci. Technol. B, vol. 19 , no. 6, pp. 2268-2279, 2001.

[18] A. C. Churchill et al., "High-mobility two-dimensional electron gases in $\mathrm{Si} / \mathrm{SiGe}$ heterostructures on relaxed $\mathrm{SiGe}$ layers grown at high temperature," Semicond. Sci. Technol., vol. 12, pp. 943-946, 1997.

[19] A. C. Churchill et al., "Two-dimensional electron gas mobility as a function of virtual substrate quality in strained $\mathrm{Si} / \mathrm{SiGe}$ heterojunctions," $J$. Vac. Sci. Technol. B, vol. 16, no. 3, pp. 1634-1638, 1998.

[20] A. J. Pidduck et al., "On the growth of high quality relaxed $\mathrm{Si}_{1-\mathrm{x}} \mathrm{Ge}_{\mathrm{x}}$ layers on Si by vapor phase epitaxy," in Proc. Inst. Phys. Conf. Ser., 1997 , no. 157 , pp. $135-144$.

[21] "Medici 2D Device Simulation Software," Avanti! Corp., Fremont, CA.

[22] "Athena 2D Process Simulation Software," Silvaco International, Santa Clara, CA.

[23] P. Kuo et al., "Comparison of boron diffusion in $\mathrm{Si}$ and strained $\mathrm{Si}_{1-\mathrm{x}} \mathrm{Ge}_{\mathrm{x}}$ epitaxial layers," Appl. Phys. Lett., vol. 62, no. 6, pp. 512-614, 1993

[24] N. Moriya et al., "Boron diffusion in strained $\mathrm{Si}_{1-\mathrm{x}} \mathrm{Ge}_{\mathrm{x}}$ epitaxial layers," Phys. Rev. Lett., vol. 71, no. 6, pp. 883-886, 1993.

[25] S. P. Voinigescu et al., "New technique for the characterization of $\mathrm{Si} / \mathrm{SiGe}$ layers using heterostructure MOS capacitors," Solid-State Electron., vol. 37, no. 8, pp. 1491-1501, 1994.

[26] E. H. Nicollian and J. R. Brews, MOS (Metal Oxide Semiconductor) Physics and Technology. New York: Wiley, 1982.

[27] Y. Taur et al., "CMOS scaling into the nanometer regime," Proc. IEEE., vol. 85, pp. 486-504, Apr. 1997. 
[28] J. L. Hoyt et al., "Strained silicon MOSFET technology," in IEDM Tech. Dig., 2002, pp. 23-26.

[29] J. P. Dismukes, L. Ekstrom, E. F. Steigmeiter, I. Kudman, and D. S. Beers, "Thermal and elastic properties of heavily doped Ge-Si alloys up to 1300 K," J. Appl. Phys., vol. 35, no. 10, pp. 2899-2907, 1964.

[30] K. A. Jenkins and K. Rim, "Measurement of the effect of self-heating in strained-silicon MOSFETs," IEEE Electron Device Lett., vol. 23, pp. $360-362$, July 2002.

[31] L. Huang et al., "Electron and hole mobility enhancement in strained SOI by wafer bonding," IEEE Trans. Electron Devices, vol. 49, pp. $1566-1571$, Sept. 2002.

[32] K. Rim et al., "Strained Si HMOSFETs for high performance CMOS technology," in VLSI Tech. Dig., 2001, pp. 59-60.

[33] S. C. Sun and J. D. Plummer, "Electron mobility in inversion and accumulation layers on thermally oxidized silicon surfaces," IEEE Trans. Electron Devices, vol. ED-27, pp. 1497-1508, Aug. 1980.

[34] Atmel.. [Online]. Available: www.atmel.com.

[35] K. Ismail, S. F. Nelson, J. O. Chu, and B. S. Meyerson, "Electron transport properties of $\mathrm{Si} / \mathrm{SiGe}$ heterostructures: Measurements and device implications," Appl. Phys. Lett., vol. 63, no. 5, pp. 660-662, 1993.

[36] S. H. Olsen et al., "Impact of virtual substrate quality on performance enhancements in strained $\mathrm{Si} / \mathrm{SiGe}$ heterojunction n-channel MOSFETs," Solid-State Electron., vol. 47, no. 8, pp. 1289-1295, 2003.

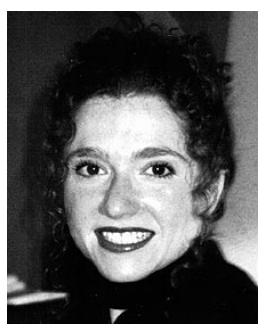

Sarah H. Olsen received the B.Sc. in physics from the University of Bath, Bath, U.K. in 1995, and the $\mathrm{Ph} . \mathrm{D}$. degree in electrical, electronic, and computer engineering from the University of Newcastle, Newcastle, U.K. in 2002.

After working as a Product Engineer at GEC Plessey Semiconductors, Plymouth, U.K., and Siemens Microelectronics, North Tyneside, U.K., she joined the University of Newcastle in 1998. Her research interests are in $\mathrm{Si} / \mathrm{SiGe}$ materials, devices and technology.

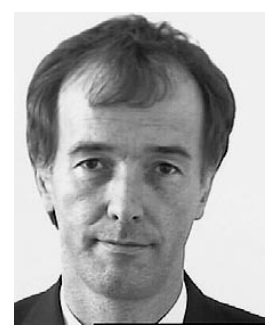

Anthony G. O'Neill received the B.Sc. degree in physics from the University of Nottingham, Nottingham, U.K., in 1980, and the Ph.D. degree from the University of St. Andrews, St. Andrews, U.K., in 1983.

He joined the University of Newcastle, Newcastle, U.K., in 1986 from Plessey Research (Caswell) Ltd., Caswell, U.K. He has worked on a wide range of topics in the field of semiconductor device and process technology and published many papers. In 1994 he was Visiting Scientist at Microsystems Technology Laboratories (MIT). He is Siemens Professor of Microelectronics and currently has research interests in strained $\mathrm{Si} / \mathrm{SiGe}, \mathrm{SiC}$, and interconnect technology.

Dr. O'Neill became a Royal Society Industrial Fellow with Atmel in 2002.

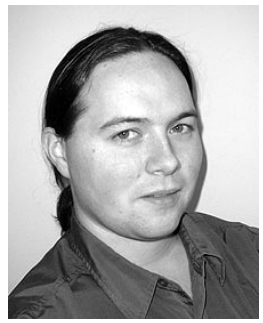

Luke S. Driscoll received the B.Eng. degree in electrical and electronic engineering from the University of Newcastle, Newcastle upon Tyne, U.K., in 2001. He is currently studying strained silicon MOSFETs while pursuing a Ph.D. degree in electrical and electronic engineering at the University of Newcastle, Newcastle upon Tyne.

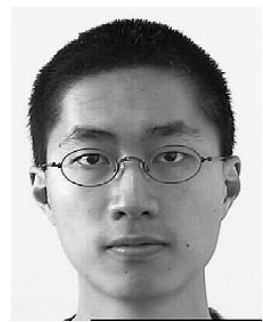

Kelvin S. K. Kwa was born in Kuala Lumpur, Malaysia, in 1978. He received the B.Eng. degree in electrical and electronic engineering from the University of Newcastle, Newcastle upon Tyne, U.K., in 2000. Since 2000, has has been pursuing the Ph.D. degree at the University of Newcastle.

His current research interests include the fabrication and characterization of strained $\mathrm{Si} / \mathrm{SiGe}$ MOSFETs, dopant diffusion in SiGe material system during processing, andgrowth and characterization of ultrathin dielectric gate materials.

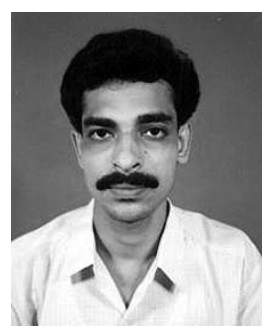

Sanatan Chattopadhyay received the B.Sc. degree in physics from the University of Calcutta, in 1992, the the M.Sc. degree in electronics science from the University of Calcutta in 1994, and the Ph.D. degree from the University of Jadavpur, Calcutta, in 1999.

From 1999 to 2001, he was working as a Post-doctoral fellow with the Singapore-Microsystems Technology Laboratories (MIT) Alliance (SMA), Singapore, before joining the University of Newcastle, Newcastle upon Tyne, U.K., as a Research Associate. His current research interests include the fabrication and characterization of strained Si/SiGe MOSFETs, low-resistive silicides/germanides for contact metallization in VLSI, and growth and characterization of ultrathin dielectric gate materials.

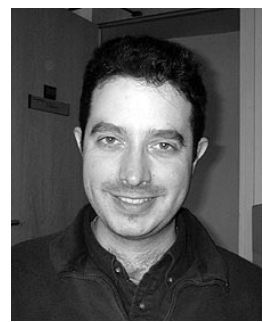

Andrew M. Waite was born in Portsmouth. U.K., on February 1, 1971. He received the B.Eng. and Ph.D. degrees from the University of Southampton, Southhampton, U.K. in 1993 and 1999, respectively. His Ph.D. work concentrated on the creation and hot carrier degradation of raised source/drain MOSFETs.

$\mathrm{He}$ was a fellow of the European Commission SUSTAIN program between 1995 and 1996, where he worked at IMEC, Leuven, Belgium. He now works as a Research Fellow at the University of Southampton, where his research interests include the integration of strained silicon into CMOS processes, pseudomorphic strained SiGe MOSFETs, and raised source/drain MOSFETs.

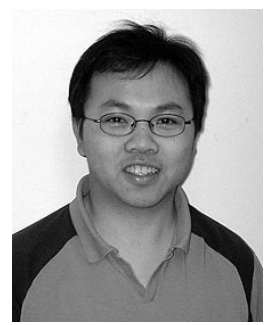

Yue T. Tang was born in Sungai Siput, Perak, Malaysia, in 1973. He received the B.Eng. degree in electronics engineering from the University of Nottingham, Nottingham, U.K., in 1995 and the M.Sc. degree in microelectronics system design and Ph.D. degree from the University of Southampton, Southampton, U.K., in 1997 and 2000, respectively. Since 2000, he has been a Post-doctoral researcher in the Microelectronics group at the University of Southampton.

From 2000 to 2001, he worked on modeling and design of heterojunction bipolar transistor on silicided SOI. Since 2001, his research interest involves design, fabrication, modeling and development of heterojunction MOS. 


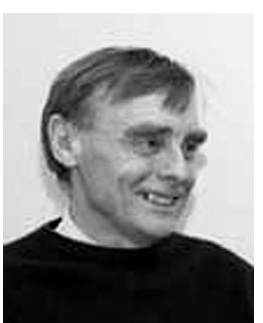

Alan G. R. Evans received the B.Sc. degree in physics from Liverpool University, Liverpool, U.K., in 1966, and the D.Phil. degree from Oxford University, Oxford, U.K. in 1969.

He has been a University academic since 1969 having worked at the Universities of Sheffield, Strathclyde, and Southampton in the U.K. He has worked on a variety of semiconductors, including InSb, InP, GaAs, SiGe, Si and polySi, studying electrical properties, device characteristics and device fabrication technologies. His recent work has been focused on MEMS devices and the use of SiGe in MOS transistors. He is a Professor with the Department of Electronics at Southampton University, Southhampton, U.K., and the Joint Head of the Microelectronics Group there. His research interests have been in the area of semiconductor materials, devices and technologies.

David J. Norris photograph and biography not available at the time of publication.

Anthony G. Cullis photograph and biography not available at the time of publication.

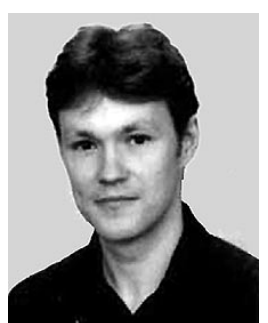

Douglas J. Paul (M'00) was born in Greenock, U.K., in 1969. He received the B.A. degree in physics and theoretical physics in 1990, the M.A. degree in physics and theoretical physics in 1994, and the Ph.D. degree in 1994, all from the University of Cambridge, Cambridge, U.K.

Since 1994, he has worked in the Semiconductor Physics Group at the Cavendish Laboratory, Cambridg,e and is presently responsible for all the $\mathrm{Si}$ and $\mathrm{SiGe}$ research. His research interests include the physics of short-channel CMOS devices, heterostructure and strained-Si CMOS, SiGe MODFETs, SiGe resonant tunneling diodes and quantum devices, $\mathrm{Si} / \mathrm{SiGe}$ quantum cascade lasers, terahertz technology, the physics of low-dimensional Si-based devices and quantum information processing. He has published over 50 publications, made over 70 presentations at conferences and holds one patent. He was one of the editors of the first edition of the Technology Roadmap of European Nanoelectronics, which has now been incorporated into the ITRS Roadmap, and he sits on a number of U.K. and EC scientific committees.

Dr. Paul is a Fellow of St Edmunds College, Cambridge, a member of the Institute of Physics and a chartered physicist.

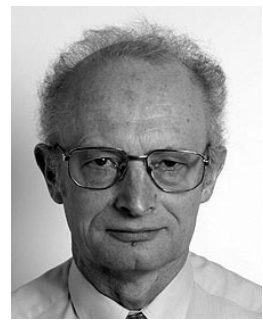

David J. Robbins received the Ph.D. degree in chemical spectroscopy from the University of East Anglia, East Anglia, U.K., in 1971.

He became a Research Fellow at Oxford University, Oxford, U.K., and joined the U.K. Ministry of Defence Research Laboratories, Malvern, U.K. in 1973, to work on CRT phosphor materials. He was a Visiting Scientist at the IBM T. J. Watson Research Center, Yorktown Heights, NY, from 1981 to 1982 , working on electroluminescent devices. After returning to Malvern, he started research in low-temperature $\mathrm{Si}$ and $\mathrm{SiGe}$ epitaxy and has led a team working on $\mathrm{SiGe}$ materials and devices for military applications since that time.

Dr. Robbins is currently a Senior Fellow in QinetiQ, Malvern, a company formed from the former U.K. defence research laboratories. He is a Fellow of the Institute of Physics. 